\title{
La transformación de una cooperativa, bajo ley estatal o vasca, en sociedad limitada o anónima
}

\author{
Iñigo Nagore Aparicio \\ Abogado economista
}

Sumario: I. Introducción. II. Posibilidades: 2.1. Regulación de estas transformaciones en la normativa mercantil. 2.2. Sociedad cooperativa regulada por Ley de Cooperativas (LCOOP). 2.3. S.Coop. regulada por la Ley de Cooperativas de Euskadi (LCE). III. Necesidad empresarial: 3.1. S.Coop. regulada por Ley de Cooperativas (LCOOP). 3.2. S.Coop. regulada por Ley de Cooperativas de Euskadi (LCE). IV. El acuerdo: 4.1. S.Coop. regulada por LCOOP. 4.2. S.Coop. regulada por LCE. V. La escritura: 5.1. S.Coop. regulada por LCOOP. 5.2. S.Coop. regulada por LCE. VI. Pasos posteriores a la elevación a público: 6.1. Sociedad Cooperativa regulada por LCOOP. 6.2. Sociedad Cooperativa regulada por LCE.

Resumen: El artículo aborda la problemática que plantea la transformación de una sociedad cooperativa, bajo ley estatal o vasca, en una sociedad anónima o limitada. Tras definir la transformación, acota el objeto del estudio y pasa a desarrollar la legislación reguladora de las posibilidades indicadas. Analiza la exigencia o no de necesidad empresarial, el acuerdo de transformación y los que puede resultar conveniente adoptar conjunta o previamente, la escritura de transformación y los documentos que la deben acompañar, así como su paso por ambos registros.

Palabras clave: Transformación de Sociedad Cooperativa. Transformación en Sociedad Anónima. Transformación en Sociedad Limitada.

Abstract: The article addresses the problems involved in converting a cooperative company into a public limited or limited company under Spanish or Basque law. After defining this conversion, the article delimits the object of study and goes on to develop legislation regulating the possibilities mentioned. It analyses the business need requirement or lack thereof, conversion agreements and those which it is suitable to adopt jointly or previously, conversion deeds and the supporting documents as well as entries in both registries.

Key words: Conversion of cooperative companies. Conversion to public limited company. Conversion to limited company. 


\section{Introducción}

Han pasado doce años desde mi anterior artículo sobre este tema. En el periodo: existe una nueva Ley de Cooperativas estatal, ha aparecido un Reglamento sobre su Registro, se ha modificado dos veces la Ley de Cooperativas de Euskadi y se la ha desarrollado reglamentariamente, se ha promulgado un nuevo Reglamento sobre su registro, hay una Ley de Sociedades de Capital y una Ley de Modificaciones Estructurales. Esto es, se ha cambiado casi totalmente la normativa aplicable por lo que resulta necesario retomar y volver a analizar el tema.

La transformación es la modificación estructural por la que una sociedad adopta un tipo social distinto, conservando su personalidad jurídica (art. 3 Ley 3/2009, de 3 de abril, sobre modificaciones estructurales de las sociedades mercantiles, BOE núm. 82, de 4 de abril de 2009, en lo sucesivo LME).

Las razones son diversas pero, si consideramos que las fórmulas jurídicas son vehículos a través de los cuales se ejecuta el objeto social, esto es el proyecto para cuyo desarrollo se constituyó, podemos decir que la transformación se realiza cuando el órgano, que va a tener que adoptar el acuerdo, considera que dicho proyecto se va a realizar mejor bajo una fórmula jurídica distinta. Normalmente en una mercantil, las razones serán sobretodo de índole económica, pero no necesariamente. A veces irán unidas a un mejor trato fiscal, otras a una redefinición de ese proyecto, o de los integrantes en el mismo, o de su participación en él, o de una comprensión sobrevenida de las limitaciones de la opción jurídica inicial... En cualquier caso, si se trata de fórmulas jurídicas que pueden elegirse libremente, sólo interesará controlar que el acuerdo fue adaptado válidamente dentro de la fórmula jurídica de origen y no las razones del mismo.

La transformación permitirá el paso directo, sin tener que disolver, liquidar y constituir una nueva. Sistema históricamente alternativo cuando no era posible la transformación, más engorroso y sobre todo caro que nos llevaba al mismo punto. Las ventajas de la transformación son indudables desde el punto de vista de tiempos, costes y mantenimiento de contratos jurídicos que no deben ser extinguidos, sino que permanecerán al continuar la personalidad jurídica.

A los efectos de este artículo limitaremos el ámbito del mismo al estudio de la transformación de una cooperativa de primer grado bajo ley estatal o vasca, en sociedad limitada o anónima. Optaré por la vasca, además de por su histórico carácter pionero, por un criterio práctico: es en la que más trabajo. 
Dado el actual sistema de legislaciones autonómicas cooperativas, extenderlo a las diversas regulaciones, realizando un estudio detallado, sería, además de una labor que superaría el ámbito de un artículo, algo casi sin sentido, muy prolijo, y que sólo sería objeto de lectura por investigadores de grandísima paciencia e interés en el derecho cooperativo comparado español, y aportaría que poco, más allá de marcar las diferencias entre las legislaciones autonómicas que algún día alguien tendrá que justificar desde el punto de vista de la administrado. Esto es, que aportan a las cooperativas de su comunidad cuando optan por regímenes fragmentarios $y$, a veces a medida, que convierten a estas en sistemas ajenos a muchos operadores y prescriptores jurídicos.

\section{Posibilidades}

Dado que la transformación implica una fórmula jurídica originaria y una fórmula final, la materia suele regularse en ambas, observándose una tendencia hacia el reconocimiento de nuevos supuestos de transformación.

La regulación actual, una vez acotado el objeto del estudio, es la siguiente:

- Regulación no cooperativa:

- Ley 3/2009, de 3 de abril, sobre modificaciones estructurales de las sociedades mercantiles, en lo sucesivo LME (BOE número 82, de 4 de abril).

- Real Decreto Legislativo 1/2010, de 2 de julio, por el que se aprueba el Texto Refundido de la Ley de Sociedades de Capital, en lo sucesivo LSC (BOE núm. 161, de 3 de julio).

- Real Decreto 1784/1996, de 19 de julio, por el que se aprueba el Reglamento del Registro Mercantil, en lo sucesivo RRM (BOE núm. 184, de 31 de julio).

- Regulación cooperativa:

- Legislación del Estado:

- Ley 27/1999, de 16 de julio, de Cooperativas, en lo sucesivo LCOOP (BOE n. ${ }^{\circ} 170$, de 17 de julio) y Real Decreto 136/2002, de 1 de febrero, por que se aprueba el Reglamento del Registro de Sociedades Cooperativas, en lo sucesivo RRCOOP (BOE núm. 40, de 15 de febrero). 
- Legislación vasca:

- Ley 4/1993, de 24 de junio, de Cooperativas de Euskadi (BOPV núm. 135, de 19 de julio); Decreto 59/2005, de 29 de marzo, de organización y funcionamiento del Registro de Cooperativas de Euskadi (BOPV n. ${ }^{\circ} 108$, de 9 de junio) y Decreto 58/2005, de 29 de marzo, por el que se aprueba el Reglamento de la Ley de Cooperativas de Euskadi (BOPV núm. 73, de 19 de abril) en lo sucesivo LCE, DRCE y DLCE respectivamente.

Cuando sólo se aplica legislación estatal, será un problema de interpretar leyes para salvar vacios o contradicciones; cuando se trata de transformar una cooperativa bajo legislación autonómica (vasca en este caso) en una mercantil, el problema, adicional, será el de la concurrencia de la competencia, constitucionalmente exclusiva del Estado, sobre la legislación de las sociedades mercantiles y el de las Comunidades Autónomas sobre las sociedades cooperativas.

\subsection{Regulación de estas transformaciones en la normativa mercantil}

Empezando el análisis por la normativa de destino (sociedad mercantil), tenemos que la específica norma estatal que regula las modificaciones estructurales de las sociedades mercantiles, LME, regula parcialmente la cuestión.

Por un lado establece en su ámbito subjetivo de aplicación (artículo 2, segundo párrafo) que: "Las modificaciones estructurales de las sociedades cooperativas, así como el traslado internacional de su domicilio social, se regirán por su específico régimen legal» y por otro, en los supuestos de posible transformación (artículo 4, número 5) que: «5. Una sociedad cooperativa podrá transformarse en sociedad mercantil, y una sociedad mercantil inscrita en sociedad cooperativa».

Refiriéndose expresamente a la transformación de una sociedad cooperativa (artículo 7, párrafo primero): «1. La transformación de una sociedad cooperativa en otro tipo social o de éste en aquélla, se regirá en lo referente a los requisitos y efectos de la transformación de la sociedad cooperativa por la legislación que le sea aplicable.»

Tenemos así que en la LME se posibilita, expresamente, la transformación de cooperativa en sociedad mercantil pero conforme a su específico régimen legal. Régimen que será el estatal o el autonómico correspondiente, según la ley cooperativa que resulte aplicable a la que se va a transformar. 
En cuanto a la LSC tenemos que, a diferencia de lo que ocurría en la LSRL, ya no hay referencias expresas a la posibilidad o no de transformarse (ahora contenidas en la ya vista LME) y que sólo hay referencias a esta, desde el punto de vista de la sociedad de capital que va a adoptar el acuerdo de su propia transformación (p.e. artículos: 160 sobre competencia de la Junta, 194 sobre quórum reforzado de constitución en casos especiales, 199 de mayoría legal reforzada para SRL o 364 derecho de separación).

El RRM contempla, en su artículo 218, el supuesto de transformación de sociedad cooperativa en limitada y, en el 224, establece un cajón de sastre dedicado a otros supuestos de transformación.

Así, no contempla expresamente la transformación de cooperativa en anónima, más allá de en el referido 224. Y ello, aún cuando no existen motivos lógicos para que el legislador no pidiese los requisitos previstos en el 218 para las limitadas, cuando se trata de anónimas. Una interpretación lógica de la norma lo exigiría, pero no su literalidad.

Debemos recordar que en la anterior legislación cooperativa estatal no estaba prevista esta posibilidad, pareciendo que le RRM ha quedado en este punto al margen de las modificaciones legislativas.

\subsection{Sociedad Cooperativa regulada por Ley de Cooperativas (LCOOP)}

Ya anunciaba los cambios en esta materia la propia Exposición de Motivos de la Ley: «Desde 1989, buena parte del Derecho de sociedades ha sido modificado, para adaptarlo a las Directivas europeas sobre la materia. Con ello, se han introducido algunas novedosas regulaciones que parece muy conveniente incorporar también a la legislación cooperativa, como las que afectan, entre otras, a la publicidad societaria, al depósito de cuentas anuales, a las transformaciones y fusiones, a las competencias de los órganos de administración y a los derechos y obligaciones de los socios.»

Su artículo destinado a la transformación (69) las autoriza en su punto primero: "Asimismo, las sociedades cooperativas podrán transformarse en sociedades civiles o mercantiles de cualquier clase. En ningún caso se verá afectada la personalidad jurídica de la entidad transformada.»

Se contempla así la posibilidad de que se transforme en ambas clases de sociedades de capital: limitadas y anónimas. 


\subsection{S.Coop. regulada por la Ley de Cooperativas de Euskadi (LCE)}

El número 1 del artículo 85 de la LCPV, autoriza la transformación de una cooperativa, regulada por tal ley, en sociedades civiles o mercantiles de cualquier clase.

Se contempla así, como en el caso anterior pero desde 1993, la posibilidad de que se transforme en ambas clases de sociedades de capital: limitadas y anónimas.

\section{Necesidad empresarial de transformación}

\subsection{S. Coop. regulada por Ley de Cooperativas (LCOOP)}

No se establecen requisitos de inviabilidad empresarial. Los socios que conformaron la voluntad de constituirse en Cooperativa, son los que sin interferencias externas deberán decidir cuando esta fórmula ya no les resulta la más conveniente. Podríamos decir, que la voluntad de los socios otorga a la cooperativa una "aplicación» del principio de puerta abierta. Permite a esta dejar de serlo cuando sus socios así lo consideren, sin tener que disolverla y liquidarla y evitando un caro y más complicado proceso. Es el reconocimiento de que la fórmula jurídica es sólo eso: una fórmula de la que se puede entrar y salir libremente.

\subsection{S. Coop. regulada por Ley de Cooperativas de Euskadi (LCE)}

Por el contrario, en la que fue pionera en esta materia LCE, se establece que «la transformación sólo podrá efectuarse por necesidades empresariales que exijan soluciones societarias inviables en el sistema jurídico cooperativo, a juicio de los administradores $y$, en su caso, de la Comisión de Vigilancia de la Cooperativa, homologado por el Consejo Superior de Cooperativas de Euskadi» (art. 85.1.a).

Dicho artículo tiene su desarrollo reglamentario en el 15 del DLCE, relativo a:

Necesidades empresariales que exijan soluciones inviables en el sistema jurídico cooperativo

El Consejo Superior de Cooperativas de Euskadi cuando adopte su acuerdo de homologación de transformación de una cooperativa en sociedad civil o mercantil, comprobará que realmente concurren 
causas de necesidad empresariales que conlleven soluciones societarias inviables en el sistema jurídico cooperativo, cuando la cooperativa se encuentre, entre otras, en cualquiera de las siguientes:

a) La necesidad acreditada de financiación ajena en la cooperativa que conlleve el control de la sociedad en función de capitales.

b) Los procesos de internacionalización debidamente acreditados que conlleven un intercambio accionarial bajo fórmulas mercantiles.

No estamos ante un supuesto de libre transformación, como el previsto en la LCOOP, sino en uno excepcional, en que sea necesario empresarialmente y no quepa otra solución jurídica.

El artículo, que fue novedoso en su momento al posibilitar la transformación de una cooperativa cuando en ningún punto del Estado era posible, ahora es, ciertamente, una restricción.

La justificación de intentar preservar la existencia de la cooperativa, no puede ser compartida por dos motivos:

1. Las leyes cooperativas están cada vez más mercantilizadas y, por ello, al igual que no cabría en una sociedad mercantil limitar la voluntad de los socios que en su día eligieron una fórmula jurídica para cambiar a otra, no debe caber limitarla en una cooperativa a la que cada vez mayor número de autores reconocen tal carácter.

2. Se sigue ejerciendo una "tutela» sobre las cooperativas, aumentándose el intervencionismo, en este caso de un órgano público (art. 145.1 LCE).

Además, no está en absoluto claro, dada la naturaleza del órgano que lo dicta y sus diversas funciones, qué recurso le queda a una cooperativa a la que no se le conceda la transformación. Y ello, aunque se de cierta seguridad jurídica a la Cooperativa al indicarse, en los acuerdos de homologación del CSCE, que contra la Resolución cabe interponer Recurso ante la jurisdicción contencioso-administrativa. Seguridad de dudosa utilidad dada la lentitud de dicha jurisdicción y, que según la propia LCE, debían existir causas que hicieran inviable la continuidad de la sociedad. ¿Puede una sociedad en tal supuesto esperar a que se resuelva dicho recurso o, de hecho, la denegación impide el recurso y obliga a buscar otras soluciones jurídicas alternativas?

En cualquier caso, son los administradores los que deben plantear la «inviabilidad» ante el «Consejo Superior de Cooperativas de Euskadi». 
Aunque no está tasada la documentación que debe acompañar a la solicitud de homologación, se ha venido exigiendo la siguiente:

a) Datos identificativos de la cooperativa. Comprenden: persona de contacto (se supone que debería ser el representante legal el que presente la solicitud), denominación, domicilio, fecha de la inscripción constituyente en el Registro de Cooperativas, actividad cooperativizada, relación de socios y fechas de incorporación de los mismos, número de trabajadores y relación de miembros del Consejo Rector.

Además, cuando existen trabajadores por cuenta ajena, se exige que se aporte declaración de los mismos, relativa a la disposición o no (en este último caso, motivada) de incorporarse a la cooperativa como socios.

b) Memoria justificativa de la transformación. En ella deben exponerse las necesidades empresariales que motivan la transformación y la imposibilidad de acometer soluciones societarias viables en el sistema jurídico cooperativo.

c) Documentación económica. Comprende: balance de sumas y saldos de los tres últimos ejercicios, balance de situación de los tres últimos ejercicios, fotocopia del impuesto de sociedades de los tres últimos ejercicios, memoria y plan de gestión (o, en su defecto, resumen de las variables empresariales más relevantes) del ejercicio en curso, balance provisional a la fecha de solicitud de la homologación, evolución del Fondo de Reserva Obligatorio y de la Contribución a la Educación y Promoción Cooperativa y de otros fines de interés público.

Dado que no existe una relación tasada de documentos, deberá aportarse todo lo que se exija, si no queremos encontrarnos con una «no homologación». Y ello, aún cuando la documentación referida pueda parecer demasiado prolija, no justificada en derecho o, por ejemplo, como el Plan de Gestión, jurídicamente insegura al no definirse por ley tal concepto.

Otra cuestión, es interpretar el sentido de la referencia que se realiza a la "Comisión de Vigilancia». Creemos que «y, en su caso» debe entenderse como que si existe tal órgano social, es preciso que se haya pronunciado favorablemente sobre la necesidad de la transformación.

En la práctica, es recomendable no someter el acuerdo de transformación propiamente dicho (o de someterlo haber condicionado este a la homologación) sino un acuerdo del Consejo Rector, en tal sentido, junto a las causas del mismo debidamente aprobadas por el y en su caso, por la Comisión de Vigilancia. Y, una vez homologada la necesi- 
dad de la transformación, proceder a llevar el tema a la Asamblea General para que adopte el acuerdo propiamente dicho.

El acuerdo de homologación suele ir condicionado a la entrega al CSCE de los Fondos Obligatorios que aparecen en el último balance aprobado.

\section{El acuerdo de transformación}

\subsection{S.Coop. regulada por $\angle C O O P$}

Establece la LCOOP, en su artículo 69 que: «2. El acuerdo de transformación de una sociedad cooperativa deberá ser adoptado por la Asamblea General, en los términos y con las condiciones establecidas en esta Ley y en los Estatutos para la fusión. Sus socios gozarán del derecho de separación en los términos previstos para el caso de fusión y al reintegro de sus aportaciones en el plazo establecido en el artículo 65. La participación de los socios de la cooperativa en el capital social de la nueva entidad habrá de ser proporcional al que tenían en aquélla. No obstante, el acuerdo de transformación en algún tipo de entidad de cuyas deudas respondan personalmente los socios, tan sólo surtirá efectos respecto de los que hayan votado a favor del acuerdo.»

Varios son los puntos abordados en este corto artículo. Los analizaremos uno a uno.

Será la Asamblea General la que debe adoptar el acuerdo en los términos y condiciones que la LCOOP y, en su caso, los estatutos sociales establezcan para la fusión (aunque debe entenderse que los Estatutos regulen la transformación de forma expresa siempre que respeten los mínimos legales establecidos para la fusión).

Si bien existe una remisión expresa al derecho de separación del artículo 65 (que luego comentaremos), la referencia a las condiciones y términos del acuerdo de transformación se hacen de forma genérica a la fusión. Dos son los artículos referidos expresamente a la fusión, siendo el 64 el que expresamente regula el acuerdo de fusión:

1. El acuerdo de fusión deberá ser adoptado en Asamblea General por cada una de las sociedades que se fusionen, por la mayoría de los dos tercios de los votos presentes y representados, ajustándose la convocatoria a los requisitos legales y estatutarios.

2. El acuerdo de fusión de cada una de las cooperativas, una vez adoptado, se publicará en el Boletín Oficial del Estado y en un diario de gran circulación en la provincia del domicilio social. 
3. Desde el momento en que el acuerdo de fusión haya sido aprobado por la Asamblea General de cada una de las cooperativas, todas ellas quedan obligadas a continuar el procedimiento de fusión.

4. La formalización de los acuerdos de fusión se hará mediante escritura pública y esta tendrá eficacia, en el Registro de Sociedades Cooperativas, para la cancelación de las sociedades que se extinguen y la inscripción de la nuevamente constituida o modificaciones de la absorbente.

De forma extractada:

- Se exigen dos tercios de los votos presentes y representados.

- La convocatoria debe cumplir los requisitos legales y estatutarios.

- El acuerdo debe publicarse en el BOE y en un diario de gran circulación del domicilio social.

— Se exige escritura pública.

¿Cuáles son los requisitos legales de la convocatoria? Entendemos se refiere a los de la fusión, previstos en el número 7 del artículo anterior:

Al publicar la convocatoria de la Asamblea General que deba aprobar la fusión deberán ponerse a disposición de los socios, en el domicilio social los siguientes documentos:

a) El proyecto de fusión.

b) Los informes, redactados por los Consejos Rectores de cada una de las cooperativas sobre la conveniencia y efectos de la fusión proyectada.

c) El balance, la cuenta de pérdidas y ganancias y la memoria explicativa de los tres últimos ejercicios de las cooperativas que participen en la fusión y, en su caso, los informes de gestión y de los auditores de cuentas.

d) El balance de fusión de cada una de las cooperativas cuando sea distinto del último anual aprobado.

Podrá considerarse balance de fusión el último balance anual aprobado, siempre que hubiera sido cerrado dentro de los seis meses anteriores a la fecha de celebración de la Asamblea que ha de resolver sobre la fusión.

e) El proyecto de Estatutos de la nueva cooperativa o el texto íntegro de las modificaciones que hayan de introducirse en los Estatutos de la cooperativa absorbente.

f) Los Estatutos vigentes de todas las cooperativas que participen en la fusión.

g) La relación de nombres, apellidos, edad, si fueran personas físicas, o la denominación o razón social si fueran personas jurí- 
dicas y en ambos casos, la nacionalidad y domicilio de los consejeros de las sociedades que participan en la fusión y la fecha desde la que desempeñan sus cargos, y en su caso, las mismas indicaciones de quienes vayan a ser propuestos como consejeros como consecuencia de la fusión.

Poco hubiera costado al legislador establecer claramente que se exige en la transformación y no dejarlo a la interpretación. Hay documentos que no tiene sentido exigir, otros que deben interpretarse y otros que no está claro y que la prudencia obligaría a realizar en defensa de los intereses de la cooperativa que va a transformarse, y ello más allá de las consultas registrales (evitar denegaciones o tener que realizar subsanaciones, etc...). Podríamos reescribirlo:

a) El proyecto de transformación. Y aquí la primera duda. ¿Es necesario? ¿Qué aporta? El artículo 63, en su punto 4, fija su contenido:

4. Los Consejos Rectores de las cooperativas que participan en la fusión habrán de redactar un proyecto de fusión, que deberán suscribir como convenio previo y contendrá al menos las menciones siguientes:

a) La denominación, clase y domicilio de las cooperativas que participen en la fusión y de la nueva cooperativa en su caso, así como los datos identificadores de la inscripción de aquéllas en los Registros de Cooperativas correspondientes.

b) El sistema para fijar la cuantía que se reconoce a cada socio de las cooperativas que se extingan como aportación al capital de la cooperativa nueva o absorbente computando, cuando existan, las reservas voluntarias de carácter repartible.

c) Los derechos y obligaciones que se reconozcan a los socios de la cooperativa extinguida en la cooperativa nueva o absorbente.

d) La fecha a partir de la cual las operaciones de las cooperativas que se extingan habrán de considerarse realizadas, a efectos contables, por cuenta de la cooperativa nueva o absorbente.

e) Los derechos que correspondan a los titulares de participaciones especiales, títulos participativos u otros títulos asimilables de las cooperativas que se extingan en la cooperativa nueva o absorbente.

Dicho artículo debería igualmente reinterpretarse, siendo algunos extremos de muy dudosa utilidad práctica.

El Consejo Rector de la cooperativa que se pretende transformar habrá de redactar un proyecto de transformación, que 
deberá suscribir y contendrá al menos las menciones siguientes:

a) La denominación, clase y domicilio de la cooperativa que se transforma, así como los datos identificadores de la inscripción de aquélla en el Registro de Cooperativa correspondiente. No se alcanza a ver su utilidad.

b) El sistema para fijar la cuantía que se reconoce a cada socio de la cooperativa como aportación al capital de la mercantil nueva, computando, cuando existan, las reservas voluntarias de carácter repartible. Es relevante y de gran utilidad especialmente por la referencia a las reservas voluntarias, pero el artículo 69 tiene ya una mención expresa al capital social de la transformada.

c) Los derechos y obligaciones que se reconozcan a los socios de la cooperativa transformada en la mercantil nueva. Sería útil de cara al derecho de información, especialmente si se trata de indicar aquellos en los que se mejore, en su caso, los mínimos legales. En otro caso, sería de más dudosa utilidad.

d) La fecha a partir de la cual las operaciones de la cooperativa habrá de considerarse realizadas, a efectos contables, por cuenta de la mercantil transformada.

e) Los derechos que correspondan a los titulares de participaciones especiales, títulos participativos u otros títulos asimilables de la cooperativa que se transforme en una mercantil.

b) El informe, redactado por el Consejo Rector de la cooperativa sobre la conveniencia y efectos de la transformación proyectada.

c) El balance, la cuenta de pérdidas y ganancias y la memoria explicativa de los tres últimos ejercicios de la cooperativa y, en su caso, los informes de gestión y de los auditores de cuentas. No tendría mucho sentido, al ser conocidos por los socios que debieron aprobarlo cada año.

d) El balance de transformación de cada cooperativa cuando sea distinto del último anual aprobado. Podrá considerarse balance de fusión, el último balance anual aprobado, siempre que hubiera sido cerrado dentro de los seis meses anteriores a la fecha de celebración de la Asamblea que ha de resolver sobre la transformación. Puede ser económicamente relevante, en todo caso, para ajustar capitales y cerrar ejercicios (el cierre generaría fondos obligatorios) 
e) El proyecto de Estatutos de la nueva mercantil.

f) Los Estatutos vigentes. No parecen necesarios.

g) La relación de nombres, apellidos, edad, si fueran personas físicas, o la denominación o razón social si fueran personas jurídicas y en ambos casos, la nacionalidad y domicilio de los consejeros de las sociedades de la transformada y la fecha desde la que desempeñan sus cargos, y en su caso, las mismas indicaciones de quienes vayan a ser propuestos como consejeros como consecuencia de la transformación.

Como hemos dicho, estas normas deben ser adecuadas a la transformación. En ella, se pretende convertir a una cooperativa de primer grado en sociedad limitada o anónima (en el objeto de este artículo). Por ello, los nuevos Estatutos Sociales serán sustancialmente distintos y creemos que debe hacerse constar, en el anuncio de la convocatoria, el derecho de examen del texto y la justificación del mismo (vía artículo 63.7.e) LCOOP o como derecho de información de los socios ante un cambio de estatutos sociales). Dichos documentos deben comprender:

- El texto de los nuevos Estatutos Sociales.

- La justificación del cambio de fórmula jurídica. En ella deberán indicarse con toda claridad todos los aspectos de los nuevos Estatutos, que no sean una mera reproducción de las normas de funcionamiento de la Sociedad Limitada o Anónima en la que pretende transformarse.

No existe limitación en cuanto a quién puede introducir en el orden del día la propuesta de transformación. Por ello, podrán hacerlo:

- El Consejo Rector (art. 23.1 y 2 de la LCOOP).

- Un número de socios que represente el 10 por 100 del total de votos, solicitando una Asamblea Extraordinaria (art. 23.2 de la LCOOP).

- Un número de socios que represente el 10 por 100 o alcance la cifra de 200, incluyéndose en la primera Asamblea que se celebre, si se presentan antes de que finalice el octavo día posterior al de la publicación de la convocatoria de la misma (art. 24.2 LCOOP).

Como hemos visto, el artículo 218 del RRM exigía para la transformación en SRL un Balance cerrado el día anterior de la transformación. Ahora bien, cuando la propuesta no la presenta el Consejo Rector, ¿quién debe realizar ese balance o el del artículo 63 de la LCOOP?

Antes de contestar la cuestión, nos hemos de plantear qué se pretende con el mismo. Esta nueva pregunta es necesaria, ya que, con- 
forme a la literalidad del 218 RRM, sólo es preciso que dicho balance se presente, junto a la escritura de transformación y otros documentos, en el Registro Mercantil, por lo que podría entenderse que no es necesario que exista previamente a la transformación y, en cualquier caso, no se menciona para las SA. Igualmente, dado el reenvío efectuado a la fusión podría igualmente discutirse si es exigible.

Creemos que, a pesar de la literalidad del artículo, debe prevalecer el sentido común y el propio interés de los socios y de los terceros afectados por la transformación (p.e. de los destinatarios de los Fondos obligatorios). Dicho balance tiene por objeto, al igual que el análogo exigido para las transformaciones mercantiles, ofrecer a los socios que van a decidir sobre el futuro jurídico de la sociedad, una mejor visión de la misma. Es más, dadas las diferencias del régimen económico societario cooperativo en relación con el de la sociedad limitada, creemos que dicho balance debe ser aprobado por la Asamblea General. Desarrollaremos este problema más adelante.

Creemos que dicho balance debe realizarlo necesariamente el Consejo Rector, por cuanto que es el único capacitado para ello.

Por otro lado, esta exigencia impediría la introducción del punto en el Orden del Día una vez convocada la Asamblea General y, sin perjuicio de que se discutiera la conveniencia de la transformación, no cabría acuerdo alguno, salvo que se convocase otra nueva Asamblea General al efecto en el menor plazo posible.

La Asamblea General estará válidamente constituida, en primera convocatoria, cuando estén presentes o representados más de la mitad de los votos sociales y, en segunda convocatoria, cuando lo estén al menos un 10 por 100 de los votos sociales o 100 votos sociales. No obstante, los Estatutos sociales pueden fijar un quórum superior o inferior, estableciendo que en segunda convocatoria quedará constituida cualquiera que sea el número de socios presentes o representados. (art. 25 LCOOP). Para la adopción del acuerdo se exigen un mínimo de dos tercios de los votos presentes y representados (art. 28).

Si la Asamblea General tiene carácter universal, entendemos podrá obviarse, aparte de la convocatoria, el informe justificativo y, en general prácticamente todo lo exigido en el reenvío a la fusión.

En cualquier caso, además de la transformación y de la aprobación del balance, en su caso, deben tomarse los siguientes acuerdos:

a) Aprobación de los nuevos Estatutos Sociales adaptados a la fórmula mercantil elegida, en nuestro supuesto limitada o anónima, con todas las menciones exigidas por ella.

b) La participación de los socios en el capital social. 
a) Menciones eXigidas pOR La LSC (ART. 23)

En los estatutos que han de regir el funcionamiento de las sociedades de capital se hará constar:

a) La denominación de la sociedad.

b) El objeto social, determinando las actividades que lo integran.

c) El domicilio social.

d) El capital social, las participaciones o las acciones en que se divida, su valor nominal y su numeración correlativa.

Si la sociedad fuera de responsabilidad limitada expresará el número de participaciones en que se divida el capital social, el valor nominal de las mismas, su numeración correlativa y, si fueran desiguales, los derechos que cada una atribuya a los socios y la cuantía o la extensión de éstos.

Si la sociedad fuera anónima expresará las clases de acciones y las series, en caso de que existieran; la parte del valor nominal pendiente de desembolso, así como la forma y el plazo máximo en que satisfacerlo; y si las acciones están representadas por medio de títulos o por medio de anotaciones en cuenta. En caso de que se representen por medio de títulos, deberá indicarse si son las acciones nominativas o al portador y si se prevé la emisión de títulos múltiples.

e) El modo o modos de organizar la administración de la sociedad, el número de administradores o, al menos, el número máximo y el mínimo, así como el plazo de duración del cargo y el sistema de retribución, si la tuvieren.

(...)

f) El modo de deliberar y adoptar sus acuerdos los órganos colegiados de la sociedad.

Comentaremos los que creemos más relevantes.

- La denominación de la sociedad. Este asunto puede resultar un verdadero problema, ya que el Registro de Cooperativas expidió la certificación negativa de denominación, indicando que no existía otra Sociedad Cooperativa con idéntica denominación a la que se pretendía adoptar (art. 33 RRCOOP) —igual ocurre con los registros autonómicos- y según el artículo 42.2 de RRCOOP que no existiese una sociedad registrada en el Mercantil en ese momento, pero no cerró éste para que no se registrase posteriormente.

Por ello, es preciso obtener un certificado de denominación en el Registro Mercantil Central antes de que se convoque la Asamblea General de transformación de la cooperativa. Ello es así, 
dado que si la denominación que se venía usando como cooperativa estuviese registrada, debería solicitarse otra y realizar junto a la transformación un cambio de denominación social.

Si la cooperativa hubiese usado la posibilidad contemplada en el número 1 artículo 396 RRM, el problema estaría resuelto, ya que mediante dicho artículo se permite la inclusión en la Sección de denominaciones del Registro Mercantil Central de las de otras entidades cuya constitución se halle inscrita en otros Registros públicos, aunque no sean inscribibles en el Registro Mercantil. Mecanismo poco usado y muy recomendable.

- Objeto social, determinando las actividades que lo integran. Dicho objeto será, en principio, el mismo.

- El capital social, las participaciones o las acciones en que se divide, su valor nominal y su numeración correlativa. Así como las demás menciones recogidas en el transcrito artículo.

Establecer el valor nominal no plantea problemas; lo que sí los crea es fijar el capital social y numerarlo cuando, por ejemplo, la legislación aplicable reconozca el derecho de separación, como es el caso y que luego analizaremos.

Sin perjuicio de lo que señalaremos al comentar esa problemática, parece claro que debe entenderse que los otorgantes de la escritura estarán autorizados a hacerlo, dando al artículo del capital social la redacción que corresponda una vez que, en su caso, los socios con derecho a separación lo hayan ejercitado. Otra interpretación obligaría a celebrar una nueva reunión de socios para reducir el capital social.

\section{b) LA PARTICIPACIÓN DE LOS SOCIOS EN EL CAPITAL SOCIAL}

El artículo 69 dentro de su número 2 establece que: «La participación de los socios de la cooperativa en el capital social de la nueva entidad habrá de ser proporcional al que tenían en aquélla.»

No deja de ser curioso que la Ley de la sociedad personalista, intente obligar a establecer el capital de la transformada en proporción al capital que los socios tenían en la cooperativa. El acuerdo se tomará en base al voto por socio, la base para el reparto de resultados y pérdidas, y así de la capitalización de resultados, podrá haber sido la actividad cooperativizada (arts. 58 y 59), pero llegado este punto la literalidad es clara.

Cuando los capitales entre los socios sean desiguales y el voto sea por socio, es muy probable que para poder adoptarse el acuerdo se tengan que previamente adoptar acuerdos modificativos del capital, 
de forma que este guarde relación con el voto de los socios. Dicho de otra forma, por mucho que la ley diga lo que dice, será muy difícil convencer a los socios que voten a favor de un acuerdo que les haga perder peso a favor de otros socios, cuando el proyecto y la inversión de futuro sean de su interés e igual ocurrirá a la inversa. La solución pasará por ajustes previos, recomendablemente en una Asamblea previa, para diferenciar ambas y evitar problemas de interpretación, de forma que la Asamblea de transformación se llegue con el capital ya arreglado.

Otro problema adicional, puede surgir en que el capital social está constituido por las aportaciones obligatorias y voluntarias de los socios (art. 45 LCOOP). ¿Es necesario establecer una diferenciación en su tratamiento a la hora de un posible acuerdo de transformación? Pensemos, por ejemplo, que no les interesaba, a tenor de los derechos económicos que conllevaban, pero sí les interesaría por los económicos y políticos que conllevará en la sociedad transformada.

No parece descabellado pensar que si en la cooperativa, el derecho de voto y de participación en resultados se ejercitan con independencia del capital, debería, a la hora de transformar, contemplar dicha problemática, al objeto de que se mantenga la proporción en la medida de los posible. Así, con carácter previo a la transformación, podría ser necesario reorganizar las aportaciones de los socios en aras a guardar la proporcionalidad en la transformación.

\section{c) OtROS ACUERDOS NECESARIOS}

Otro problema es la existencia de un Fondo de Reserva repartible (art. 58.3) o pérdidas pendientes de compensar con retornos (art. 59.3).

Creemos que es necesario acomodar el régimen económico cooperativo al de las limitadas o las anónimas, según sea la opción. Así, será preciso que la Asamblea General acuerde el reparto de dicha reserva o su capitalización y se compensen las pérdidas pendientes.

Además, al transformar a SRL será preciso exigir el desembolso de todas las aportaciones pendientes (art. 78 LSC).

\section{d) DeRECHO de SEPARACIÓN}

La LCOOP (art. 69.2) reconoce el derecho de separación de los socios en los términos previstos para el caso de fusión y al reintegro de sus aportaciones en el plazo establecido en el artículo 65.

Esto es, reconoce, a los socios de las cooperativas que se transformen y que no hubieran votado a favor, el derecho a separarse de su 
cooperativa, mediante escrito dirigido al Presidente del Consejo Rector, en el plazo de cuarenta días desde la publicación del anuncio del acuerdo, según lo previsto en misma Ley y antes detallado.

Respecto de ellos, la sociedad resultante de la transformación asumirá la obligación de la liquidación de las aportaciones al socio disconforme, en el plazo regulado en esta Ley para el caso de baja justificada y según lo establecieran los Estatutos de la cooperativa de la que era socio y respetando lo dispuesto como mínimo en el artículo 51 de la LCOOP.

\subsection{S.Coop. regulada por $L C E$}

\section{a) DISPOSICIONES COOPERATIVAS}

La letra b) del número 1 del artículo 85 de la LCE exige acuerdo «expreso y favorable, de la Asamblea General, adoptado con los requisitos establecidos para modificar los Estatutos».

Su artículo 74 regula dicha modificación exigiendo los siguientes requisitos:

a) Informe escrito formulado por los autores de la propuesta con justificación de la misma.

b) Que se expresen en la convocatoria, con la debida claridad los extremos a modificarse.

c) Que en el anuncio de la convocatoria se haga constar expresamente el derecho de todos los socios a examinar en el domicilio social el texto íntegro de la modificación propuesta y del informe justificativo de la misma y de pedir la entrega o envío gratuito de dichos documentos.

Obviamente, dado que cabe transformación en sociedad civil o mercantil de cualquier clase, debe precisarse a cual pretende transformarse.

La propuesta será presentada por el Consejo Rector, a iniciativa propia o a petición de socios que representen, al menos, el 20 por 100 del total de los votos. Si se solicita la inclusión en el orden del día por socios que representen más del 10 por 100 del total de votos, en los cinco días siguientes al anuncio de convocatoria, existirán los obstáculos que comentamos el referirnos a la regulación de la LCOOP (art. 33 LCE).

La Asamblea General, salvo la de carácter universal, estará válidamente constituida, en primera convocatoria, cuando estén presentes o 
representados la mayoría de votos, y en segunda convocatoria cuando lo estén al menos socios que ostenten el 10 por 100 de los votos o cien votos, bastando, salvo previsión estatutaria en contra, alcanzar dicho quorum al inicio de la sesión (art. 34.2 LCE).

El acuerdo de transformación debe ser tomado, por mayoría de dos tercios de los votos presentes o representados, cuando el número de votos presentes y representados sea inferior al 75 por 100 del total de votos de la Cooperativa.

En otro caso, basta la mitad de los votos válidamente emitidos, no computándose los en blanco ni las abstenciones (art. 36 LCE).

Respecto a la conversión de aportaciones al capital social, se establece la posibilidad de realizarla «en proporción directa al capital que tuviera desembolsado cada socio en la Cooperativa, al derecho de voto que ostentaba en la misma, o bien combinando ambos criterios (art. 85.5 LCE). Posibilitando así adecuar los capitales de la nueva, según sean el deseo de los socios que integran la cooperativa, de una forma más flexible que la legislación estatal.

La LCE distingue entre socios, socios de trabajo, socios colaboradores, socios inactivos o no usuarios (arts. 19 a 30).

Cada socio tiene derecho a un voto. No obstante, en las Cooperativas de primer grado los Estatutos pueden prever que el derecho de voto de los socios que sean Cooperativas, sociedades controladas por éstas y entidades públicas, sea proporcional a la actividad Cooperativa con la sociedad o las prestaciones complementarias a esta actividad en el marco de la intercooperación. El número de votos de un socio que no sea sociedad cooperativa, no puede ser superior al tercio de los votos totales de la Cooperativa (art. 35.1 y 2 LCE).

Respecto a la necesidad de homogeneizar el régimen económico de la transformada, la casuística es un poco distinta por serlo el régimen de la LCE.

Así, existen Fondos de Reserva Voluntarios repartibles sin vencimiento (art. 67.2.c.2), cuentas sin individualizar de pérdidas y cuentas individualizadas a compensar con cargo a futuros retornos (art. 69).

Creemos que será preciso armonizar las primeras y las terceras, cabiendo mantener las segundas.

b) LSC

Les resulta de aplicación lo ya visto para las que se encuentran bajo LCOOP, artículo 23 de la LSC. 


\section{La escritura}

La inscripción del acuerdo exige la oportuna escritura pública que entre otros acuerdos y como más relevante, contendrá el de transformación. El artículo 19 LME condiciona la eficacia de la transformación a la inscripción de la oportuna escritura en el Registro Mercantil.

\subsection{S. Coop. regulada por $\angle C O O P$}

El artículo 9 del RLCOOP en su número 1, punto 9, cita como actos inscribibles los acuerdos de transformación sin distinguir explícitamente entre los de «transformación de» o los de «transformación en». Su artículo 11, regulador de los actos inscribibles, exige escritura pública para la inscripción de la transformación en una cooperativa, no mencionando inscripción alguna para la transformación de una cooperativa en su letra e), aunque podría entenderse que este dentro de la k), que establece otros supuestos de inscripción que se establezcan por Ley y sea preceptiva la formalización del acto por escritura pública.

Habida cuenta que la «transformación de la cooperativa en» debe cumplir, desde el momento que se acuerda, la regulación de la transformada y que la propia transformación se regula de forma incompleta en la LCOOP, mediante una remisión parcial a la fusión, la regulación no está suficientemente clara en cuanto a sus requisitos.

Antes de la LSC, la escritura pública se exigía por el número 2 del artículo 93 de la LSRL y el número 1 del 218 del RRM para la transformación en sociedad limitada. Ahora sólo queda la referencia del 218 del RRM, al haber desaparecido la de la LSRL en la LSC y no aparecer expresamente en la LME.

Dada la inexistencia de regulación específica para la transformación de sociedades cooperativas en sociedades anónimas, creemos que debe aplicarse de forma supletoria el citado 218 RRM también a tal supuesto.

Ahora bien, cabe que la Asamblea que tome el acuerdo de transformación haya tomado previamente algún acuerdo únicamente inscribible en el de cooperativas o que afecta al balance que se vaya a usar en la transformación para, por ejemplo, fijar los capitales. En este caso, cabe separar, en distintas escrituras, los acuerdos que sólo afecten a un registro de los que sólo afecten a otro $y$, a veces, para evitar problemas registrales, celebrar Asambleas Generales distintas, una para los acuerdos previos a la transformación y otra para la transformación propiamente dicha. 
Las certificaciones del acta se expiden con las firmas del Secretario y del Presidente. El acta debe estar previamente aprobada.

No obstante, es frecuente que junto al acuerdo de transformación se tome un acuerdo de cese y posterior nombramiento de administradores, siendo el mismo de obligatoria inscripción. Se plantearía un problema cuando se haya modificado en los Estatutos de la nueva forma societaria la composición del órgano, pasándose, por ejemplo, de Consejo de Administración a Administrador Único. En estos casos, entiendo debe aplicarse el artículo 109 del RRM y dado que el certificante no estará inscrito, el 111.

La elevación a público sólo podrán realizarla personas que tengan facultad para certificarlos (art. 108.1 y 2 del RRM).

El contenido de la certificación deberá cumplir las exigencias del artículo 112 del RRM, transcribiéndose el mismo y haciendo constar todas las circunstancias del acta, necesarias para calificar la validez de los acuerdos adoptados.

Recordemos que dada la diferencia de funcionamiento entre sociedades limitadas/anónimas y cooperativas, figurará el número de socios de éstas, no siendo necesario indicar el capital que representan. No obstante, para evitar problemas es recomendable que conste dicho capital, incluso con referencia al correlativo artículo de la LCOOP a fin de indicar dicha normativa.

Por otro lado, el RRM, en su artículo 218, y el 18 de la LME, exigen que la escritura pública contenga:

a) Las menciones previstas para la constitución de una sociedad cuyo tipo se adopte (art. 18.2 LME).

Dichas menciones son (art. 22 LSC):

- La identidad del socio o socios.

- La voluntad de constituir una sociedad de capital, con elección de un tipo social determinado.

- Las aportaciones que cada socio realice o, en el caso de las anónimas, se haya obligado a realizar, y la numeración de las participaciones o de las acciones atribuidas a cambio.

- Los estatutos de la sociedad.

- La identidad de la persona o personas que se encarguen inicialmente de la administración y de la representación de la sociedad.

- Además, si la sociedad fuera de responsabilidad limitada, la escritura de constitución determinará el modo concreto en que inicialmente se organice la administración, si los estatutos prevén diferentes alternativas. 
- Y si la sociedad fuera anónima, la escritura de constitución expresará, además, la cuantía total, al menos aproximada, de los gastos de constitución, tanto de los ya satisfechos como de los meramente previstos hasta la inscripción.

Las anteriormente mencionadas, deben ser adaptadas a la transformación.

Respecto a la voluntad de constituir una sociedad, no constará la misma, sino que la Asamblea General adoptó el acuerdo de transformarse en sociedad limitada.

Igualmente, no constarán las aportaciones que cada socio realizó, sino las que existían a su nombre en el momento de acordarse la transformación.

b) La relación de socios que hubieran hecho uso del derecho de separación y el capital que representen, así como el balance final cerrado el día anterior al otorgamiento de la escritura (arts. 18.2 LME y 218.2 RRM).

Ya hemos analizado el derecho de separación y, en cuanto, al balance final cerrado, nos remitimos a lo que más adelante indicaremos.

c) Las acciones o las participaciones que se atribuyan a cada socio en la sociedad transformada, según sea la fórmula jurídica elegida (art. 18. 2 LME).

d) Si las normas sobre la constitución de la sociedad cuyo tipo se adopte así lo exigieran, se incorporará a la escritura el informe de los expertos independientes sobre el patrimonio social (art. 18.3 LME). Informe exigido para las sociedades anónimas en el artículo 67 LSC.

e) El consentimiento de todos los socios que tengan en la cooperativa algún tipo de responsabilidad personal por las deudas sociales (art. 218.1 RRM).

En este sentido debe recordarse el artículo 15.3 de la LCOOP, que establece que la responsabilidad de los socios por las deudas sociales se limitará a las aportaciones al capital social que hubieran suscrito.

f) La manifestación de los otorgantes, bajo su responsabilidad, de que el patrimonio cubre el capital social quedando éste totalmente desembolsado (art. 218.1 RRM). Debe ponerse en relación con lo señalado en la letra d) para las anónimas.

Esta doble manifestación puede obligar a que previamente se haya realizado un saneamiento de la sociedad y a que lógicamente, si se transforma en SRL, se hayan exigido los desembolsos pendientes o reducido el capital. 
A estos efectos, puede resultar aconsejable la presentación de un informe de los auditores de la cooperativa, en su caso, sobre la adecuación entre la cifra de capital y el valor patrimonial de la sociedad.

g) La manifestación de los otorgantes, bajo su responsabilidad, de que los acreedores sociales han consentido expresamente la transformación, cuando dicho supuesto se haya producido (art. 218.1 RRM).

Dada la remisión del artículo 69 a las condiciones y términos de la fusión, y el derecho de oposición reconocido en esta a los acreedores (art. 66):

\section{Artículo 66. Derecho de oposición de los acreedores}

La fusión no podrá realizarse antes de que transcurran dos meses desde la publicación del anuncio del acuerdo de fusión. Durante este plazo, los acreedores ordinarios de cualquiera de las sociedades cuyos créditos hayan nacido antes del último anuncio de fusión, y que no estén adecuadamente garantizados, podrán oponerse por escrito a la fusión, en cuyo caso ésta no podrá llevarse a efecto si sus créditos no son enteramente satisfechos o suficientemente garantizados. Los acreedores no podrán oponerse al pago aunque se trate de créditos no vencidos.

En la escritura de fusión los otorgantes habrán de manifestar expresamente que no se ha producido oposición alguna de acreedores con derecho a ella o, de haber existido, manifestar que han sido pagados o garantizados sus créditos, con identificación en este caso de los acreedores, los créditos y las garantías prestadas.

Deberá o bien esperarse el plazo, o conseguir el acuerdo, o prestar las garantías. En una sociedad con actividad y gran número de acreedores se optará, normalmente, por dejar transcurrir el plazo.

h) Las normas que han sido aplicadas para la adopción del acuerdo de transformación, así como el destino dado a los fondos o reservas que tuviere la entidad (art. 218.2 RRM).

La mención a las normas aplicadas no parece referida a las circunstancias necesarias para calificar la validez de los acuerdos adoptados, que ya comentamos, deben aparecer a nuestro juicio, en el certificado (art. 112.1 y 2 RRM). Así, por normas (y dada la variedad legislativa a que puede estar sometida la cooperativa), parece referirse a la necesidad de que se indique la legislación cooperativa. En tal sentido se exige en la transformación inversa (de sociedad limitada a sociedad cooperativa, art. 222.2.b) RRM).

En cuanto al destino de los fondos o reservas debe recordarse que las normas de la transformación (art. 69.6 LCOOP) establecen que en 
el supuesto de transformación de una sociedad cooperativa en otro tipo de entidad, los saldos de los fondos de reserva obligatorio, el fondo de educación y cualesquiera otro fondo o reservas que estatutariamente no sean repartibles entre los socios, recibirán el destino previsto en el artículo 75 de esta Ley para el caso de liquidación de la cooperativa.

Y el citado artículo 75, en su número 2, señala que el haber líquido sobrante, si lo hubiere, se pondrá a disposición de la sociedad cooperativa o entidad federativa que figure expresamente recogida en los Estatutos o que se designe por acuerdo de Asamblea General. De no producirse designación, dicho importe se ingresará a la Confederación Estatal de Cooperativas de la clase correspondiente a la cooperativa en liquidación y de no existir la Confederación correspondiente, se ingresará en el Tesoro Público, con la finalidad de destinarlo a la constitución de un Fondo para la Promoción del Cooperativismo.

Establece además, que si la entidad designada fuera una sociedad cooperativa, ésta deberá incorporarlo al fondo de reserva obligatorio, comprometiéndose a que durante un período de quince años tenga un carácter de indisponibilidad, sin que sobre el importe incorporado se puedan imputar pérdidas originadas por la cooperativa. Si lo fuere una entidad asociativa, deberá destinarlo a apoyar proyectos de inversión promovidos por cooperativas.

Por último, se reconoce a cualquier socio de la cooperativa en liquidación que tenga en proyecto incorporarse a otra cooperativa, el derecho a exigir que la parte proporcional del haber líquido sobrante de la liquidación, calculada sobre el total de socios, se ingrese en el fondo de reserva obligatorio de la sociedad cooperativa a la que se incorpore, siempre que así lo hubiera solicitado con anterioridad a la fecha de la convocatoria de la Asamblea General que deba aprobar el balance final de liquidación. Puede discutirse si este derecho al socio, cabe reconocérselo al que optó por la separación para integrarse en otra cooperativa.

\subsection{S.Coop. regulada por $L C E$}

Como ya vimos, la LCE regulaba la transformación, existiendo, además, un Decreto regulador del Registro de Cooperativas de Euskadi (DRCE) muy similar al RRM.

En dicho DRCE aparece como objeto de inscripción la transformación (art. 32.1.g), exigiéndose, para practicarla, escritura pública (art. 33.1). 
La documentación de los acuerdos sociales es regulada de forma similar al RRM, destacándose que sólo se faculta para elevar a público los acuerdos sociales a quienes lo estén para certificarlos (art. 34 DRCE), y que, en su caso, es necesario que conste en la certificación el dictamen favorable del letrado asesor de la sociedad.

Se exige que consten en la escritura pública:

a) Las menciones legal y reglamentariamente exigidas para la constitución de la entidad cuya forma se adapte, respetando lo dispuesto en la LCE (arts. 85.1.d LCE y 59.3 DRCE). Nos remitimos a lo comentado al respecto al analizar la LCOOP, en lo que se refiere a transformación en Sociedad Limitada o Anónima.

b) El informe de los expertos independientes sobre el patrimonio social no dinerario, previsto en la legislación mercantil, en su caso (arts. 85.1.d LCPV y 59.4 DRCE). Aplicable para la transformación en Sociedad Anónima según vimos anteriormente.

Respecto al momento en que debe realizarse el informe, parece lógico pensar que el mismo debe estar a disposición de los socios en el momento de la convocatoria de la Junta.

c) La relación de socios que hayan ejercitado el derecho de separación y el capital que representen (arts. 85.1, segundo párrafo de la LCPV y 59.3.f del DRCE).

Dicho derecho se reconoce a los socios que hayan votado en contra del acto de la Asamblea, o a los que, no habiendo asistido a la misma, expresen su disconformidad mediante escrito dirigido a los administradores en el plazo de cuarenta días desde la publicación del último anuncio del acuerdo (veremos que se exige publicación en el Boletín Oficial del País Vasco y en dos periódicos de gran circulación en el territorio histórico -Álava, Guipúzcoa o Vizcaya- en que la Cooperativa tenga su domicilio art. 85.1.c) LCE). A tales socios se les reconoce el derecho al reembolso de sus aportaciones al capital en el plazo que, sin exceder de cinco años y desde la fecha del acuerdo de transformación, determinen los Estatutos o acuerde la Asamblea, percibiendo el interés legal del dinero por las cantidades aplazadas (art. 85.3 LCE).

Vemos así, que se les reconoce un derecho de separación limitado, al no devolvérsele de forma inmediata el importe de sus aportaciones, sino en un máximo de cinco años.

En parte de los supuestos, no será interesante usar este derecho por resultar más rentable e incluso rápido vender las participaciones o acciones de la transformada. 
d) Como ya indicamos, la Asamblea General puede optar por convertir las aportaciones al capital social en participaciones económicas de la nueva entidad, en proporción directa al capital que tuviera desembolsado cada socio en la Cooperativa, al derecho de voto que ostentaba en la misma Cooperativa, o bien combinando ambos criterios (art. 85.5 LCE).

e) La homologación del Consejo Superior de Cooperativas de Euskadi (art. 59.3.a) del DRCE). En la práctica suele estar condicionada a la entrega de los fondos de Reserva Obligatorios y fondos irrepartibles.

f) Acuerdo expreso y favorable de la Asamblea General de la Cooperativa, adoptado por mayoría de dos tercios de los votos presentes o representados, siempre que el número de votos presentes o representados sea inferior al 75 por 100 del total de votos de la Cooperativa (arts. 36.2 LCE y 59.3.b) del DRCE). Dicho acuerdo irá dentro del certificado o del acta notarial.

g) Acreditación del cumplimiento del informe escrito justificativo de la propuesta modificación de estatutos inherente a la transformación, de la expresión en la convocatoria de los extremos a modificar y de que en el anuncio de la convocatoria se haya hecho constar expresamente el derecho de todos los socios a examinar en el domicilio el texto íntegro de la misma y de pedir la entrega o el envío gratuito de dichos documentos (arts. 74.2 de la LCE y 59.3.C) del DRCE).

Realmente, gran parte de estos extremos eran necesarios para calificar la validez del acuerdo (art. 34.2 DRCE), por lo que el artículo es, parcialmente, reiterativo. Además, cuando la Asamblea tenga carácter universal no será necesario acreditar ninguno de los mismos.

h) Justificación de la publicación del acuerdo de transformación en el Boletín Oficial del País Vasco y en dos periódicos de gran circulación del Territorio Histórico del domicilio social de la Cooperativa (art. 59.3.d) del DRCE).

La LCE exigía dichos anuncios, pero no que se incorporasen a la escritura (art.85.1.b de la LCE).

Los anuncios en los periódicos no plantean problemas, dado que es posible su publicación de un día para otro. No ocurre lo mismo con el del Boletín Oficial del País Vasco.

i) Balance cerrado el día anterior al del acuerdo de transformación o bien al finalizar el último ejercicio, si hubieren transcurrido menos de seis meses desde el cierre del mismo y hubiese sido depositado en el 
domicilio social a disposición de los socios desde el mismo día en que se cursó la convocatoria de la Asamblea General (art. 59.3.e) DRCE).

El balance, como en el caso anterior, se exigía en el artículo 85.1.e) de la LCE, pero no su incorporación a la escritura pública.

Una vez más, el tema ha sido estudiado en relación a la cooperativa bajo LCOOP. Debemos aquí analizar la influencia del mismo en la determinación de la cuota de liquidación del socio que hace uso, en su caso, del derecho de separación e incluso de su posible influencia en la determinación de los fondos de reserva irrepartibles. Así, este balance plantea las siguientes cuestiones:

Primera: ¿Es meramente informativo o debe ser aprobado por los socios?

Habida cuenta de las distintas reglas que rigen en la cooperativa y en las limitada o anónima, parecería lógico que se cerrase balance a la fecha de aprobar la transformación y se distribuyesen los resultados de la cuenta de pérdidas y ganancias. Y es que el resultado de la distribución es radicalmente distinto en una cooperativa que en un SA o SRL, y también lo es en una cooperativa bajo LCOOP (arts. 57 a 59) que otra bajo LCE (arts. 67 y 69).

Por un lado, los intereses de los socios serán distintos en función de la cuantía que les corresponde como retorno en la cooperativa o del dividendo o incremento de valor de su participación o acción en la limitada o anónima, respectivamente, según hubiese quedado repartido el capital tras la transformación y según se haya cerrado o no el balance y distribuido los resultados.

Además, aparte de los propios socios, existe un futuro acreedor interesado, ya que una distribución de, por ejemplo, excedentes significa un incremento de los fondos irrepartibles a entregar.

Segunda: Habida cuenta de que, de haber procedido a efectuar una liquidación, el activo sobrante del haber social (art. 75 LCOOP y art. 94.2.d) LCE), si lo hubiere, así como el remanente del Fondo de Educación y Promoción y otros fines de interés social, debían haberse entregado aplicado según lo establecido en cada Ley ¿basta optar por la transformación para conseguir que por ejemplo las plusvalías tácitas de los elementos del activo inmovilizado pasen a la sociedad transformada y, por ello, a los socios o debe reflejar este balance con exactitud y claridad el estado patrimonial de la Sociedad, como en la liquidación (arts. 74 de la LCOOP y 95.1 de la LCE)?

El sentido común debería decantarnos por esta última solución, dado que en otro caso la transformación sería un perfecto medio legal para burlar las disposiciones cooperativas relativas a la liquidación. 
El único problema sería el alto peaje a pagar por la empresa que realizara la transformación y los problemas financieros que el mismo le ocasionaría, problemas que se solucionarían en gran medida mediante las cuentas en participación (art. 85.4 LCE).

Así, es preciso realizar dos puntualizaciones:

- Por un lado, cuando la LCE introdujo la posibilidad de la transformación, exigió la homologación previa, por lo que no cabía usarla como mero elemento de evadir fondos irrepartibles, ni plusvalías tácitas en balance. Es al liberalizarlo en la LCOOP cuando se permite la situación.

- Por otro, tampoco es lógico que, aunque debe mediar homologación, esos cantidades queden para los socios.

El problema es que, aún cuando el criterio expuesto sobre el balance sea lógico, no creemos que resulte, con la LCE ni con la LCOOP, defendible. La primera no realiza mención alguna en este sentido, sino más bien al contrario, al señalar que el valor nominal será lo que debe acreditarse (art. 85.4) y la segunda, indica sólo que recibirán el destino establecido en caso de liquidación (art. 69.4 con reenvío al 75 de la LCOOP).

j) Acreditación de la aplicación de la Contribución a la Educación y Promoción Cooperativa y otros fines de interés social, así como del acuerdo asambleario sobre los Títulos en cuentas de participación que pudieran corresponder al Consejo Superior de Cooperativas de Euskadi (art. 59.3.g) del DRCE).

Al igual que en los balances, se exige la inclusión en la escritura por el DRCE.

La LCE (art. 85.4) dispone que la Contribución para la Educación y Promoción Cooperativa y otros fines de interés social tiene la aplicación estatutariamente prevista y, en su defecto, se pone a disposición del Consejo Superior de Cooperativas de Euskadi. Igualmente señala que el valor nominal de las dotaciones del Fondo de Reserva Obligatorio y de las reservas voluntarias irrepartibles, se acreditan al Consejo Superior de Cooperativas de Euskadi como títulos de cuentas en participación, referidos a la sociedad resultante del proceso transformador, debiendo adoptar la oportuna decisión.

k) Además, debería constar, en su caso, en el certificado del acuerdo que se eleva a público, el dictamen del letrado asesor sobre si los acuerdos son ajustados a derecho cuando la sociedad venga obligada a acreditar sus cuentas (art. 73.2 LCE). 


\section{Pasos posteriores a la elevación a público}

\subsection{Sociedad Cooperativa regulada por LCOOP}

El artículo 218.3 del RRM exige que en la transformación de sociedad cooperativa en sociedad de responsabilidad limitada se acompañe a la escritura, para su depósito en el Registro Mercantil:

a) Un balance general cerrado el día anterior al del acuerdo de transformación. Ya comentado al referirnos al mismo.

b) La certificación del Registro de Cooperativas correspondiente, en la que consten la inexistencia de obstáculos para la inscripción de la transformación y, en su caso, la transcripción literal de los asientos que hayan de quedar vigentes. Además, constará en la certificación la nota de cierre provisional de la hoja de la cooperativa que se transforma.

¿Significa esto que el Registro de Cooperativas no califica y que ante un acuerdo de transformación se limita a realizar una anotación preventiva y extender el certificado para que el Registro Mercantil pueda certificar?

El artículo 218.4 del RRM indica que, una vez inscrita la transformación en el Registro Mercantil, éste lo comunica de oficio al de Cooperativas para que proceda a la cancelación de los asientos de la sociedad.

¿Se exige una calificación previa del Registro de Cooperativas para emitir dicho certificado, con examen de los documentos pertinentes o basta una solicitud para su emisión? Dada la literalidad del artículo (del Registro Mercantil) y la ausencia de regulación expresa en el de Cooperativas, creemos debe interpretarse de forma literal, evitándose una doble calificación. Esto es, que bastará la solicitud de que se emita certificado en este sentido y ello salvo que alguno de los acuerdos complementarios alteren los asientos sobre los que se debe certificar la vigencia. Y ello, aún cuando en la práctica suponga dejar el cumplimiento de las formalidades previstas en la LCOOP en manos del RM.

c) Además, si la legislación cooperativa aplicable a la cooperativa que se transforma exigiere algún tipo de publicidad escrita del acuerdo, deben acompañarse los ejemplares de las publicaciones en que la misma se hubiere realizado. Por remisión a las condiciones y términos de las fusiones: anuncio en el $B O E$ y periódico de gran circulación en la provincia del domicilio (art. 64.2 LCOOP).

Una vez inscrita la transformación de la cooperativa, el Registrador Mercantil debe comunicar de oficio al Registro de Cooperativas corres- 
pondiente para que en éste se proceda a la inmediata cancelación de los asientos de la sociedad.

Por último, el artículo 225 del RRM establece que en la inscripción de la transformación deben consignarse, además de las circunstancias generales, todas aquellas exigidas para la inscripción primera de la Sociedad, cuya forma se adapte, así como aquellas otras relativas al derecho de separación de los socios que sean procedentes.

Los datos relativos a la primera inscripción de la sociedad en Registro Mercantil se publicarán en el BORME, Sección 1. ${ }^{a}$ Empresarios, apartado «actos inscritos» en los términos indicados en los artículos 421 y 387 del RRM.

\subsection{Sociedad Cooperativa regulada por $L C E$}

El artículo 85, número 1, letra e), indica que la escritura debe ser presentada, sucesivamente, tanto en el Registro de Cooperativas, para inscribir la baja correspondiente, como, en su caso, en el Registro Mercantil para la inscripción primera de la entidad cuya forma se adopte.

En el mismo sentido se pronuncia el número 2 del artículo 59 del DRCE cuando señala que, para la cancelación registral de los asientos de la Cooperativa que se transforma, se presentará en el Registro de Cooperativas de Euskadi escritura pública de transformación con acreditación, en su caso, de la inscripción en el Registro Mercantil.

Adicionalmente, se presentan problemas con el certificado del Registro de Cooperativas por el procedimiento registral utilizado por este: sucinto con remisión al archivo correspondiente en el que constará el documento (art. 20.1 DRCE). El Registro Mercantil necesitará el documento base para poder realizar los correspondientes asientos que se mantendrán vigentes.

Igualmente se realizará la publicación en el BORME indicada en el punto anterior. 